\title{
Gastric Histopathology of Chronic Gastritis in Obese Patients Undergoing Laparoscopic Sleeve Gastrectomy: A Local Experience
}

\author{
Murad A. Alturkustani, FRCPC, MBBS \\ Department of Pathology, Faculty of Medicine \\ King Abdulaziz University, Jeddah, Saudi Arabia
}

\section{Correspondence}

Dr. Murad A. Alturkustani

P.O. Box 80205, Jeddah 21589, Saudi Arabia

e.M: maltarkustani@kau.edu.sa

Submission: 15 Jan. 2017

Accepted: 19 Feb. 2017

\section{Citation}

Alturkustani MA. Gastric histopathology of chronic gastritis in obese patients undergoing laparoscopic sleeve gastrectomy: A local experience. JKAU Med Sci 2017; 24 (2): 9-15 DOI: 10.4197/Med. 24.2.2

\begin{abstract}
A retrospective review was conducted using the database at King Abdulaziz University Hospital, to determine the most common cause of chronic gastritis among obese individuals. One hundred and thirtyone specimens were examined, obtained from patients who had laparoscopic sleeve gastrectomy and diagnosed with chronic gastritis. Helicobacter pylori was detected in 15 cases only. The most common diagnosis was "Chronic inactive gastritis without Helicobacter pylori infection" in 57 (43.50\%) cases, then "Chronic gastritis with lymphoid follicular hyperplasia" in 54 (41.20\%) cases, and lastly "Chronic active gastritis" in the remaining 20 (15.20\%) Cases. The low incidence of Helicobacter pylori infection even in cases of gastritis with lymphoid follicular hyperplasia support the existence of the new proposed entity (i.e., obesity-related gastritis). Biopsy specimens for cases diagnosed as chronic gastritis were used as control group to confirm the appropriate rate of detecting Helicobacter pylori organisms by morphological examination in the same laboratory. In these biopsies, Helicobacter pylori was present in $(50.70 \%)$, and reactive follicular hyperplasia was detected in (6\%) of total controls.
\end{abstract}

\section{Keywords}

Gastritis; Obesity; Laparoscopic Sleeve Gastrectomy;

Helicobacter pylori

\section{Introduction}

$T$ he recent increase of bariatric surgeries offered an excellent source for obtaining gastric specimens of obese patients. Histological examination of these specimens resulted in many incidental findings, the most common was features of chronic gastritis ${ }^{[1,2]}$. However, the most common cause of this gastritis (i.e., no specific etiology) was different from the most common cause of chronic gastritis in gastric biopsies (i.e., Helicobacter pylori (H. pylori) infections) ${ }^{[3]}$. The latter observation proposed a new form of chronic gastritis, the obesity-related gastritis ${ }^{[4]}$.

Furthermore, chronic gastritis with follicular hyperplasia is consistently associated with $H$. pylori infection. The organisms are often detected on biopsy examination of patients' specimens. Accordingly, the presence of follicular hyperplasia was thought to be exclusive to $H$. pylori infection ${ }^{[5]}$. In addition, these reactive lymphoid follicles were also considered as the 
precursor for gastric Mucosa Associated with Lymphoid Tissue (MALT) lymphoma ${ }^{[6]}$. However, this association was not this strong in gastric specimens obtained from bariatric surgeries.

This study aims to determine the most common cause of chronic gastritis among obese patients who had laparoscopic sleeve gastrostomy (LSG), attending a tertiary care hospital in western Saudi Arabia, and establish the association between chronic gastritis with follicular hyperplasia, and H. pylori infection in the specimens of obese individuals.

\section{Methods}

Approval from the Research Ethics Board of King Abdulaziz University was obtained prior to the study. A retrospective review was conducted using the electronic database of the pathology department at King Abdulaziz University Hospital. As the study focused on obese patients, data was collected from all specimens of LSGs, performed in the period between 2011 and 2015. Histopathological reports upon examining gastric tissue specimens of these patients were reviewed. Within the pathological report, attention was given for gross examination, microscopic findings, performance of special stains to detect $H$. pylori and the final diagnosis. This was followed by targeted selection of cases to re-examine the specimens, and confirm the diagnosis, after which we clarified any obscure points in the pathology report. I included only cases with the pathological diagnosis of chronic gastritis, with or without lymphoid hyperplasia and excluded cases with specific etiology of the chronic gastritis other than $\mathrm{H}$. pylori infection (e.g., autoimmune gastritis). Another cohort of the 150 routine gastric biopsies, diagnosed in 2015 as chronic gastritis, was included in the study as controls only to confirm the appropriate rate of detecting $\mathrm{H}$. pylori organisms by morphological examination in the same laboratory. The diagnosis of controls was confirmed using the same laboratory testing of the cases, and we also estimated the frequency of $H$. pylori infection and follicular gastritis in the control specimens.

The following definitions were used in this study for different types of gastritis. Chronic gastritis; "Gastric mucosa infiltrated by a significant number of lymphocytes and plasma cells in the lamina propria (i.e., more than only scattered cells)". This can be classified into A. Chronic inactive gastritis: when the chronic inflammation is not associated with acute inflammatory cells in the gastric pits and or foveolae; $\mathrm{B}$.
Chronic active gastritis: where morphological features of chronic gastritis are detected, in addition to the presence of acute inflammatory cells (i.e., neutrophils) in the gastric pits and foveolae; and C. Chronic gastritis with follicular hyperplasia (also known as follicular gastritis): when this inflammation is accompanied by the presence of lymphoid follicles with germinal centers. Helicobacter pylori detection in this study was mainly performed using hematoxylin and eosin (H\&E) special stain, and by cresyl fast violet special stain if the organisms were suspected but not primarily detected by $H \& E$ stain.

\section{Results}

During this period 131 specimens, obtained from LSGs met the inclusion criteria, and under the broad diagnosis of chronic gastritis. These included 98 females and 33 males. The age ranged between $18-66$, with a mean age of (34.4) year. Helicobacter pylori was detected in 15 cases only. The most common histopathological diagnosis reported was "Chronic inactive gastritis without H. pylori infection" in 57 (43.5\%) cases. (Fig. 1A, B) The second most common diagnosis was "Chronic gastritis with lymphoid follicular hyperplasia" (Fig. 1C, D) assigned to $54(41.2 \%)$ cases. For the latter cases, H. pylori organisms were present in only four out of the total 54 cases. "Chronic active gastritis" was the diagnosis reported for the remaining 20 (15.2\%) cases, and $H$. pylori organisms was present in 11 out of these 20 cases. For the control group H. pylori was present in $76(50.7 \%)$ out of 150 cases, and reactive follicular hyperplasia was detected in only nine (6\%) cases of the total controls.

In summary, the most significant findings from testing specimens from LSG were: the lower incidence of $H$. pylori as a cause of chronic gastritis, the high frequency of chronic gastritis with lymphoid follicular hyperplasia, and low association of the latter finding with H. pylori infection.

\section{Discussion}

Chronic gastritis refers to the chronic inflammation of gastric mucosa, whether due to infectious or a non-infectious etiology. Among these, H. pylori infection is considered the most common cause ${ }^{[3]}$. Histopathological examination of the gastric mucosa provides important clues about possible causes, and can present conclusive features such as: corpusrestricted inflammation with atrophy in autoimmune 

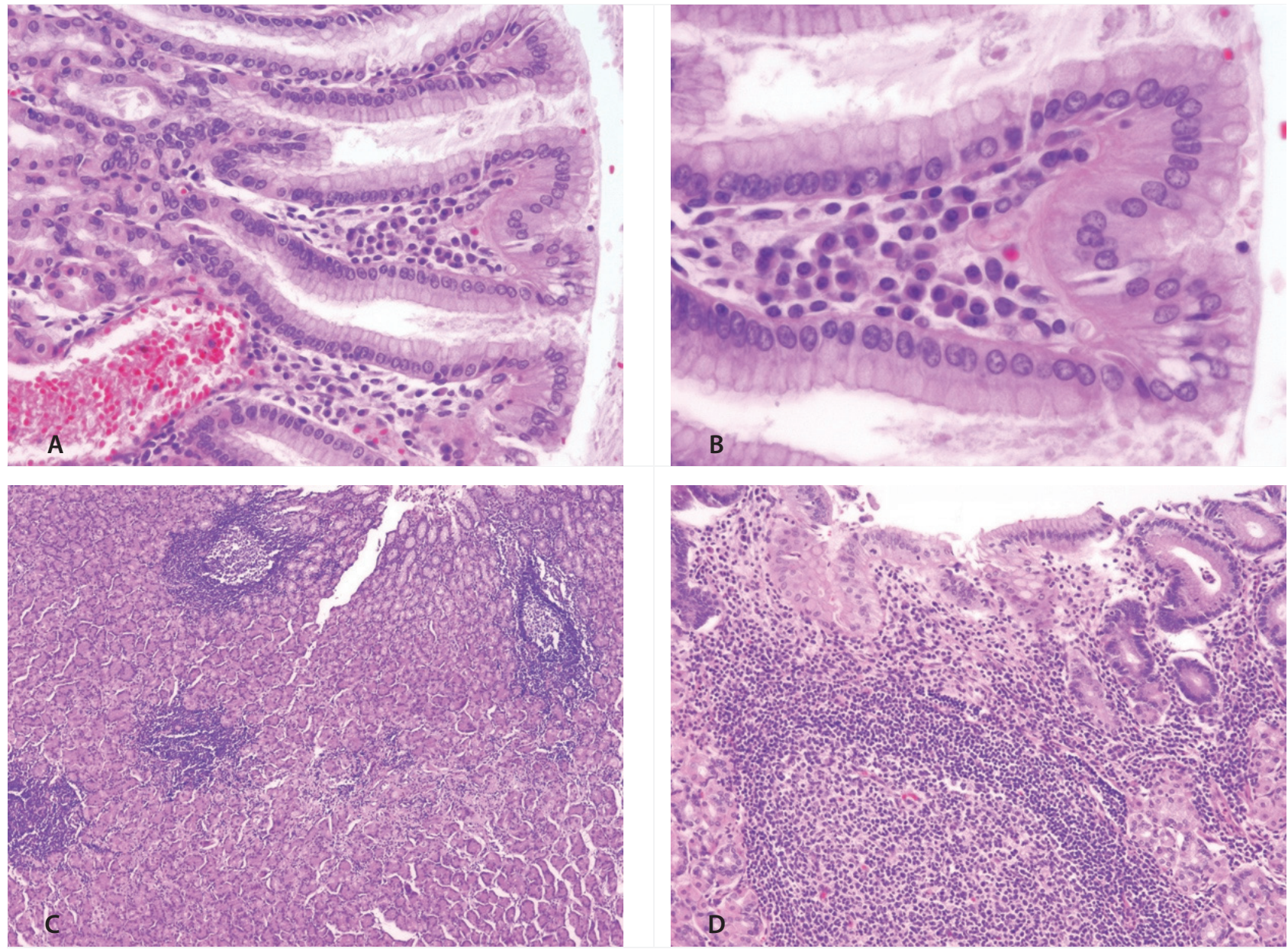

Figure 1. Histopathology of chronic gastritis. (A, B) Chronic inactive gastritis with lymphoplasmacytic infiltrate in the lamina propria with no acute inflammatory cells (H\&E; original magnification A: 200x, B: 400x). (C, D) Chronic gastritis with lymphoid follicular hyperplasia showing multiple lymphoid follicles with reactive germinal centers and chronic inflammatory cells in the lamina propria (H\&E; original magnification A: 40x, B: 100x).

gastritis, prominent intraepithelial lymphocytic infiltrate without significant neutrophils in lymphocytic gastritis, granulomas in different types of granulomatous gastritis, and reactive mucosal changes that lack significant inflammation in different forms of gastropathy. Despite the above, a small proportion of chronic gastritis remains with no identifiable etiology, even when obtaining detailed clinical information and performing meticulous histological examination ${ }^{[7]}$. This proportion is more prominent in gastric specimens from morbidly obese patients who underwent bariatric surgery.

Chronic gastritis with follicular hyperplasia is defined as: "The presence of reactive lymphoid follicles (i.e., follicles with germinal center)", which is easily recognized in a biopsy screening, and considered a strong indicator of $H$. pylori presence. The detection of this organism requires careful and high-power examination of the slides. The frequency of detection of $H$. pylori in cases of chronic gastritis with follicular hyperplasia ranges from very high, to almost all cases after thorough slides' examination ${ }^{[8]}$. In fact, presence of follicular hyperplasia was thought to be exclusive to H. pylori infection ${ }^{[5]}$. Lymphoid follicles are associated with specific response to chronic antigenic stimulation elicited by the organisms, and thus support the specificity of this type of reaction to H. pylori infection ${ }^{[8]}$. Furthermore, lymphoid follicle formation is also proved to be the precursor for MALT lymphoma, and thus $H$. pylori is strongly associated with this type of lymphoma ${ }^{[6]}$. 
In LSG specimens, chronic gastritis with follicular hyperplasia has a weak association with $H$. pylori infection, as found in the current study, with only $4(7.4 \%)$ of 54 cases demonstrating identifiable organisms. This finding is consistent with the lower rates of $H$. pylori infection in this type of specimens collected from different populations, and as previously demonstrated in two more studies. The first study found only 26 cases of $H$. pylori, in a total of $95(27 \%)$ chronic gastritis cases with follicular hyperplasia ${ }^{[7]}$, while the second study reported only 13 cases of $H$. pylori in $78(16.6 \%)$ cases of chronic gastritis with follicular hyperplasia ${ }^{[1,9]}$. On the other hand, a more recent study found a high percentage of $H$. pylori infection (84\%), among individuals diagnosed with follicular gastritis, and who underwent $\mathrm{LSG}^{[2]}$. Helicobacter pylori was a very common finding in this study $(40.9 \%)$, despite treating all patients with a positive Campylobacter-like organism test, with the standard triple therapy prior to the surgery, which is expected to lower the prevalence of $H$. pylori in these specimens. Furthermore, the frequency of $H$. pylori was also high, and namely (74\%), among' specimens with lymphoid aggregates only ${ }^{[2]}$. This may explain the high percentage of $H$. pylori infections in their cohort, as opposed to ours and the other two studies.

Chronic gastritis with follicular hyperplasia is strongly associated with lymphoid tissue lymphoma (MALT) of the gastric mucosa, and chronic gastritis with follicular hyperplasia is considered exclusive to the $H$ pylori infection ${ }^{[5]}$. The fact that chronic gastritis with follicular hyperplasia occurs in obese individuals, and in the absence of $H$. pylori infection, raises the possibility to consider morbid obesity as a risk factor for MALT lymphoma. Supporting this possibility is a recently published case report documenting the presence of gastric MALT lymphoma in morbidly obese patients with no $\mathrm{H}$. pylori infection, and after complete remission and successful weight reduction by gastric bypass and resection ${ }^{[10]}$. Further research is needed to assess this association, and draw better conclusions.

Although $H$. pylori is reported as the most common cause of gastritis ${ }^{[3]}$, it is not thoroughly documented among chronic gastritis patients. Of the limited instances where it is examined, $H$ pylori infections were of a high percentage among patients with chronic gastritis. Furthermore, it was shown to be the prime cause of chronic gastritis in 292 (65.9\%) patients in one study ${ }^{[11]}$, and in $78 \%$ of gastritis patients in another study ${ }^{[12]}$. This comes in agreement with our study, where the control cohort reported a prevalence of $50.7 \%$ of H. pylori in the biopsies of chronic gastritis. This is in contrast with the LSG specimens, where H. pylori was only present in 15 out of 131 cases, i.e., (11.5\%). Congruent to this are results from a recent review by Verma et al., ${ }^{[13]}$. They found that the frequency of $H$. pylori, although generally low in these specimens, had a variable prevalence across subgroups ranging from $11.5 \%-66.7 \%$. Other studies which came after this review again confirmed this lower rate (Table 1), except for the study by Safaan et al., ${ }^{[2]}$ as discussed above. The latter observation along with higher incidence of chronic gastritis in specimens from bariatric surgeries, led to a proposal by Yamamoto et al., ${ }^{[4]}$ for a new entity of gastritis, i.e., the obesity-related gastritis. The latter could explain the discrepancy between $\mathrm{H}$. pylori incidence between all biopsies and those from patients who underwent LSGs.

Obesity is considered a state of chronic low-grade inflammation ${ }^{[14]}$. Recent studies linked the inflammatory state of obesity, to the many co-morbidities associated with it. This includes hypertension, diabetes and several neoplasms ${ }^{[15]}$. Another observation confirming this inflammatory characteristic of obesity, is the fact that weight loss is often associated with reductions of

Table 1. Studies on the frequency of gastritis with follicular hyperplasia* in obese patients undergoing bariatric surgery.

\begin{tabular}{|c|c|c|c|c|c|c|c|}
\hline \multirow[t]{2}{*}{ Study } & \multirow{2}{*}{$\begin{array}{l}\text { Total No. of } \\
\text { Cases }\end{array}$} & \multicolumn{2}{|c|}{$\begin{array}{c}\text { Chronic Inactive } \\
\text { Gastritis }\end{array}$} & \multicolumn{2}{|c|}{ Chronic Active Gastritis } & \multicolumn{2}{|c|}{ Follicular Lymphoid Hyperplasia } \\
\hline & & Total & H. pylori & Total & H. pylori & Total & H.pylori \\
\hline Present study & 131 & 57 & 0 & 20 & 11 & 54 & 4 \\
\hline Safaan et al. ${ }^{[2]}$ & 1555 & 512 & NA & 105 & 67 & 43 & 37 \\
\hline Almazeedi et al. ${ }^{[1]}$ & 656 & 488 & 6 & 49 & 12 & $95^{\mathrm{a}}$ & 26 \\
\hline Raess et al. ${ }^{[9]}$ & 248 & 30 & NA & NA & NA & 78 & NA \\
\hline Vrabie et al. ${ }^{[17]}$ & 87 & NA & NA & 20 & NA & 29 & NA \\
\hline
\end{tabular}

Abbrv.: H. pylori = Helicobacter pylori; NA: Not Available; * Only studies that specified the number of follicular lymphoid hyperplasia under chronic gastritis were included in this table.

a: Active \& inactive 
the above comorbidities ${ }^{[15]}$. This type of inflammation is not linked to infections or autoimmune stimulus. This inflammatory status was attributed to several elevated inflammatory mediators such as; Interleukin six (IL-6) and Tumor Necrosis Factor a (TNFa). Accordingly, it is likely that these chronic inflammatory cells which are flared up in obesity, can explain the higher incidence of chronic gastritis in bariatric surgery specimens, namely those not likened to $H$. pylori infections.

A major limitation to acknowledge is related to the detection of $H$. pylori organisms in the sampled specimens. The strong association of $H$. pylori and chronic gastritis with follicular hyperplasia was demonstrated, and this emphasizes the thoroughness needed when examining specimens. However, the large size of specimens derived from LSG may have affected the findings due to the following reasons: (1) The large surface area of the LSG specimens available for examination. This may give a better chance to identify follicular hyperplasia, especially when it is easily detectable by low power examination of the slides. (2) Microscopically, these specimens are not optimal for detection of $\mathrm{H}$. pylori, and the larger the surface area is, the more difficult to examine it thoroughly by high magnification. (3) The nature of these specimens such as the antrum, where it is the most likely area to harbor $\mathrm{H}$. pylori organisms, were not included in these specimens. Despite the latter, the histopathological detection of $\mathrm{H}$. pylori organisms in these specimens was not likely affected by these factors, and this was confirmed when detection by other sensitive means such as serology, also revealed similar $H$ pylori rates among these patients. The latter was emphasized by Verma et al. ${ }^{[13]}$ in a review of previous studies focusing on $\mathrm{H}$. pylori infections in bariatric patients. Another limitation was the lack of data on status of patients who were diagnosed and treated for H. pylori prior to the LSG. However, none of the included patients had a gastric biopsy in our institution before the surgery for this purpose, and the high percentage of chronic gastritis in LSG specimens favor that they did not receive a treatment for $H$. pylori prior to the procedure.

In conclusion, $H$. pylori infection was found to be a much less common cause of chronic gastritis among patients who underwent LSG, and most of the chronic gastritis cases were of no identifiable cause, and thus supporting the proposal of an obesity-related gastritis. Chronic gastritis with follicle formation has only weak association with $H$. pylori infection in LSG specimens, proposing that this type of inflammation is part of a morphological spectrum in the obesity-related gastritis, and that chronic gastritis is not restricted to $\mathrm{H}$. pylori infection alone. The latter may also mark obesity as a possible risk factor for MALT lymphoma. However, more researches in this field is required to prove or deny this possibility.

\section{Conflict of Interest}

The author has no conflict of interest.

\section{Disclosure}

The author did not receive any type of commercial support either in forms of compensation or financial for this study. The author has no financial interest in any of the products or devices, or drugs mentioned in this article.

\section{Ethical Approval}

Obtained.

\section{References}

[1] Almazeedi S, Al-Sabah S, Al-Mulla A, Al-Murad A, Al-Mossawi A, Al-Enezi K, Jumaa T, Bastaki W. Gastric histopathologies in patients undergoing laparoscopic sleeve gastrectomies. Obes Surg 2013; 23(3): 314-319.

[2] Safaan T, Bashah M, El Ansari W, Karam M. Histopathological changes in laparoscopic sleeve gastrectomy specimens: prevalence, risk factors, and value of routine histopathologic examination. Obes Surg 2017; 27 (7): 1741-1749.

[3] Dixon MF, Genta RM, Yardley JH, Correa P. Classification and grading of gastritis. The updated Sydney System. International Workshop on the Histopathology of Gastritis, Houston 1994. Am J Surg Pathol 1996; 20(10): 1161-1181.

[4] Yamamoto S, Watabe K, Takehara T. Is obesity a new risk factor for gastritis? Digestion 2012; 85(2): 108-110.

[5] Isaacson PG. Recent developments in our understanding of gastric lymphomas. Am J Surg Pathol 1996; 20 Suppl 1: S1-7.

[6] Ahmad A, Govil Y, Frank BB. Gastric mucosa-associated lymphoid tissue lymphoma. Am J Gastroenterol 2003; 98(5): 975-986.

[7] Sepulveda AR, Patil M. Practical approach to the pathologic diagnosis of gastritis. Arch Pathol Lab Med 2008; 132(10): 1586-1593.

[8] Genta RM, Hamner HW, Graham DY. Gastric lymphoid follicles in Helicobacter pylori infection: frequency, distribution, and response to triple therapy. Hum Pathol 1993; 24(6): 577-583. 
[9] Raess PW, Baird-Howell M, Aggarwal R, Williams NN, Furth EE. Vertical sleeve gastrectomy specimens have a high prevalence of unexpected histopathologic findings requiring additional clinical management. Surg Obes Relat Dis 2015; 11(5): 1020-1023.

[10] Helman R, Teixeira PP, Mendes CJ, Szego T, Hamerschlak N. Gastric MALT lymphoma and grade II obesity: gastric bypass surgery as a therapeutic option. Obes Surg 2011; 21(3): 407-409.

[11] Adlekha S, Chadha T, Krishnan P, Sumangala B. Prevalence of Helicobacter pylori infection among patients undergoing upper gastrointestinal endoscopy in a medical college hospital in kerala, India. Ann Med Health Sci Res 2013; 3(4): 559-563.

[12] Tarkhashvili N, Beriashvili R, Chakvetadze N, Moistsrapishvili M, Chokheli M, Sikharulidze M, Malania L, Abazashvili N, Jhorjholiani E, Chubinidze M, Ninashvili N, Zardiashvili T, Gabunia U, Kordzaia D, Imnadze P, Sobel J, Guarner J. Helicobacter pylori infection in patients undergoing upper endoscopy, Republic of Georgia. Emerg Infect Dis 2009; 15(3): 504-505.

[13] Verma S, Sharma D, Kanwar P, Sohn W, Mohanty SR, Tortolani AJ, Gorecki P. Prevalence of Helicobacter pylori infection in bariatric patients: a histologic assessment. Surg Obes Relat Dis 2013; 9(5): 679-685.

[14] Lumeng CN, Saltiel AR. Inflammatory links between obesity and metabolic disease. J Clin Invest 2011; 121(6): 21112117.

[15] Cottam DR, Mattar SG, Barinas-Mitchell E, Eid G, Kuller L, Kelley DE, Schauer PR. The chronic inflammatory hypothesis for the morbidity associated with morbid obesity: implications and effects of weight loss. Obes Surg 2004; 14(5): 589-600.

[16] Clapp B. Histopathologic findings in the resected specimen of a sleeve gastrectomy. JSLS 2015; 19(1): e2013.00259.

[17] Vrabie CD CM, Waller M, Sindelaru R, Copaescu C. The main histopathological gastric lesions in obese patients who underwent sleeve gastrectomy. Dicle Med J Cilt 2010; 37(2): 97-103 


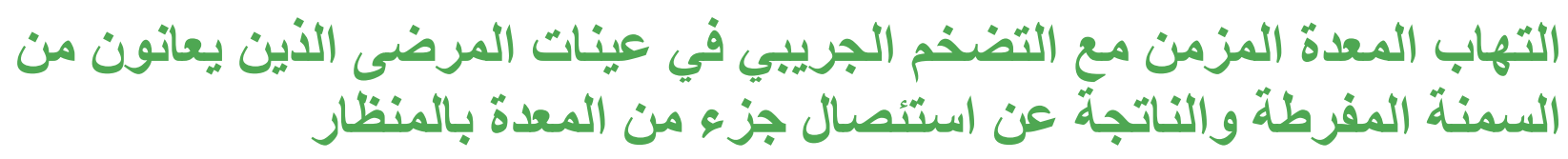

$$
\begin{aligned}
& \text { مراد عبدالكريم التركستاني }
\end{aligned}
$$

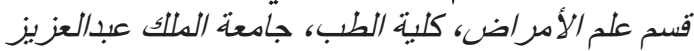

$$
\begin{aligned}
& \text { جلة ـ المدلكة العربية السعودية العابة }
\end{aligned}
$$

المستخلص. تم إجر اء مر اجعة بأثر رجعي عينات المرضى الذين يعانون من السمنة المفرطة والناتجة عن إستئصال جزء

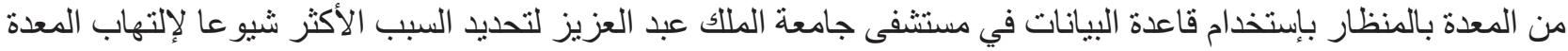

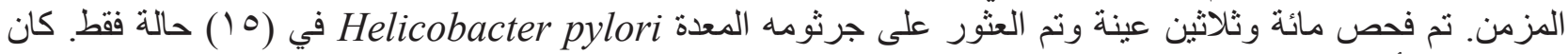

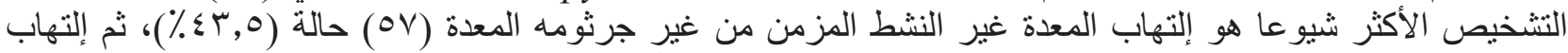

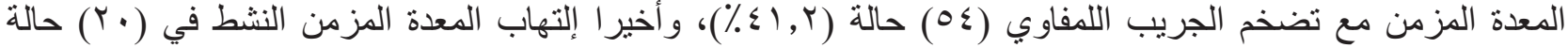

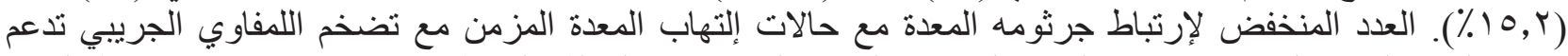

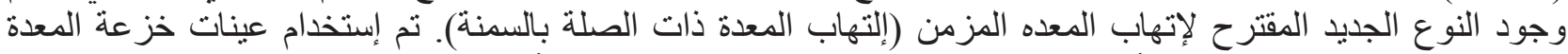

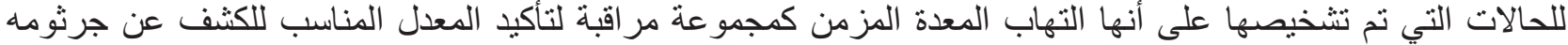

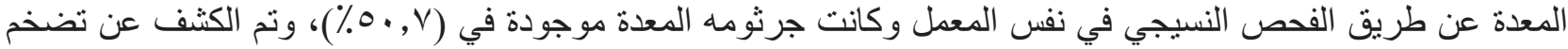

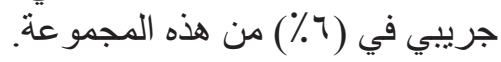

